\title{
EFFECTS OF EXTRACTANTS ON ANAL YTICAL CHARACTERISTICS AND PYROLYSIS GAS CHROMATOGRAPHY OF PODZOL FULVIC ACIDS
}

\section{F. MARTIN}

Centro de Edafología y Biología Aplicada, Cortijo de Cuarto, C.S.I.C., Sevilla (Spain)

(Received February 20, 1975; revised and accepted December 3, 1975)

\section{ABSTRACT}

Martin, F., 1976. Effects of extractants on analytical characteristics and pyrolysis gas chromatography of Podzol fulvic acids. Geoderma, 15: 253--265.

Fulvic acids extracted from the $\mathrm{B}_{\mathbf{h}}$ horizon of a Podzol with three reagents: $\mathrm{NaOH}$, $\mathrm{HCl}$ and the mixture $\mathrm{Na}_{4} \mathrm{P}_{2} \mathrm{O}_{7} / \mathrm{NaOH}$, show no significant differences by physical and chemical analysis with the exception of the $\mathrm{N}$-content of the $\mathrm{NaOH}$ extract and the $E_{4} / E_{6}$ ratios of those extracted with $\mathrm{HCl}$ and $\mathrm{Na}_{4} \mathrm{P}_{2} \mathrm{O}_{7} / \mathrm{NaOH}$, indicating that these fulvic acids have very few condensed aromatic nuclei structures.

Pyrolysis gas chromatography of the three fulvic-acid specimens produces the same low-boiling-point compounds, but in different amounts. Various alkanes and olefins as well as other compounds have been identified. By pyrolysis of the methylated fulvic acids, it has been shown that part of the resulting compounds are produced by reactions of component radicals. The main pyrolysis reaction appears to be dehydration. The pyrolysis patterns of the three fulvic-acid specimens provide evidence that there are some differences in structure not evident from conventional physical and chemical analysis.

\section{INTRODUCTION}

In studies of soil humic substances, the discrepancies in the data are due, among other factors, to the variety of extractants and to the criteria applied to ensure pure extracts (Dubach and Mehta, 1963).

When different extractants are used and the same methods of purification are applied, the physico-chemical characteristics of the isolated humic compounds may be different (Posner, 1966; Theng et al., 1967; Butler and Ladd, 1969; Jacquin et al., 1970; Ortiz de Serra and Schnitzer, 1972; Vila et al., 1974). Apparently this occurs with humic substances from some types of soil but not others. For Podzols, one fraction of humic substances, the fulvic acids, are not measurably different when they are isolated with acid or alkaline reagents (Schnitzer and Skinner, 1968).

In the present paper I have evaluated the effects of three extractants: $0.5 \mathrm{~N} \mathrm{NaOH}, 0.5 \mathrm{~N} \mathrm{HCl}$ and $0.1 M \mathrm{Na}_{4} \mathrm{P}_{2} \mathrm{O}_{7} / \mathrm{NaOH}(1: 1)$, on the analytical characteristics of fulvic acids (FA) extracted from a Podzol $\mathrm{B}_{\mathrm{h}}$ horizon. Comparisons were made by physical, chemical and thermal degradation methods. 
This last method has been scarcely used in studies of FA (Wershaw and Bohner, 1969) although, in the opinion of Guiochon (1968), "it is a rapidly expanding and very promising method for the analysis of polymers".

\section{MATERIAL AND METHODS}

Specimens of FA were extracted from the $B_{h}$ horizon of a Podzol from the vicinity of Ribadeo, Spain. The profile description is as follows:

\begin{tabular}{|c|c|c|c|c|}
\hline \multicolumn{2}{|c|}{$\begin{array}{l}\text { Classification } \\
\text { Location } \\
\text { Elevation } \\
\text { Topography } \\
\text { Orientation } \\
\text { Parent material } \\
\text { Vegetation }\end{array}$} & \multicolumn{3}{|c|}{$\begin{array}{l}\text { humic-ferric Podzol } \\
\text { Ribadeo, Lugo (Spain) } \\
210 \mathrm{~m} \text { above sea level } \\
\text { undulating to hilly } \\
\mathrm{S} \\
\text { sandy schist } \\
\text { heather, reforested with pine }\end{array}$} \\
\hline Horizon & \multicolumn{2}{|c|}{ Depth $(\mathrm{cm})$} & Description & $\because$ \\
\hline $\begin{array}{l}A_{00} \\
A_{0}-A_{1}\end{array}$ & \multicolumn{2}{|c|}{$\begin{array}{l}0-5 \\
5-15\end{array}$} & $\begin{array}{l}\text { partly decom } \\
\text { black ( } 5 \text { YR } 2 \\
\text { acid : }\end{array}$ & $\begin{array}{l}\text { ed forest litter } \\
\text { friable; raw humus with remains of ferns; }\end{array}$ \\
\hline $\begin{array}{l}A_{2} \\
B_{h}\end{array}$ & \multicolumn{2}{|c|}{$\begin{array}{l}15-30 \\
30-35\end{array}$} & $\begin{array}{l}\text { gray (10YR } 5 \\
\text { dark reddish } \\
\text { organic; acid }\end{array}$ & $\begin{array}{l}\text {; sand; friable; homogeneous; slightly acid } \\
\text { Wn (5YR 3/2); sand; crumbly; friable; very }\end{array}$ \\
\hline $\begin{array}{l}\mathrm{B}_{\mathrm{S}} \\
\mathrm{C}_{1}\end{array}$ & \multicolumn{2}{|c|}{$\begin{array}{l}35-50 \\
50-\end{array}$} & $\begin{array}{l}\text { light brown ( } \\
\text { sandy schist }\end{array}$ & YR 6/4); sand; spotted by organic matter \\
\hline
\end{tabular}

Some general characteristics of the $\mathrm{B}_{\mathrm{h}}$ horizon are: (1) grain-size distribution: $58 \%$ (2-0.2 $\mathrm{mm}$ class), $17 \%(0.2-0.02 \mathrm{~mm}$ class $) ; 18 \%(0.02-0.002 \mathrm{~mm}$ class $)$ and $6 \%(<0.002 \mathrm{~mm}$ class $) ;(2) \mathrm{pH}\left(\mathrm{H}_{2} \mathrm{O}\right)=3.3$; and (3) C-content $=6.6 \%$.

\section{Extraction with $0.5 \mathrm{~N} \mathrm{NaOH}$}

Two hundred grams of air-dried soil sample were suspended in water to eliminate roots. The water was decanted and the soil was extracted under constant agitation with $1 \mathrm{l}$ of $0.5 \mathrm{~N} \mathrm{NaOH}$ solution for $24 \mathrm{~h}$ in a sealed bottle. The air in the bottle was displaced by oxygen-free nitrogen prior to extraction. After centrifugation, the supernatant was removed. The soil residue was extracted repeatedly in this way.

Supernatants, containing the soluble materials, were treated with resin (Dowex 50. W, $\mathrm{H}^{+}$form), after which the precipitated humic acids (HA) and the resin were separated by filtration. The FA solution was twice treated with fresh resin, the water eliminated in a rotary evaporator at $40^{\circ} \mathrm{C}$, and the solids dried in a desiccator over silica-gel. The purified FA weighed $8.6 \mathrm{~g}$ which was equivalent to $75 \%$ of the organic matter in the original soil sample. 


\section{Extraction with $0.5 \mathrm{~N} \mathrm{HCl}$}

Two hundred grams of air-dried soil sample were treated in the same way as for the $\mathrm{NaOH}$ extraction.

The $\mathrm{pH}$ of the $\mathrm{HCl}$ solution, after extraction of $\mathrm{FA}$, was adjusted to 4 with $1 N \mathrm{NaOH}$, thus precipitating the $\mathrm{Fe}$ and $\mathrm{Al}$ salts. The coagulate was dialyzed till free of $\mathrm{Cl}^{-}$and then agitated with resin, following the procedure described above. The yield was $8.6 \mathrm{~g}$, also representing $75 \%$ of the original organic matter.

\section{Extraction with $0.1 \mathrm{M} \mathrm{Na}_{4} \mathrm{P}_{2} \mathrm{O}_{7} / \mathrm{NaOH}(1: 1)$}

The same quantity and the same general procedure was followed as described for $\mathrm{NaOH}$ and $\mathrm{HCl}$.

The FA solution was adjusted to $\mathrm{pH}=2$ with $\mathrm{H}_{2} \mathrm{SO}_{4}$. The coagulated $\mathrm{HA}$ was separated by centrifugation and the remaining FA solution was adsorbed onto charcoal and eluted according to Forsyth (1947). The yield was $8.0 \mathrm{~g}$, representing $69.6 \%$ of the original organic matter.

\section{Analytical methods}

$\mathrm{C}$ and $\mathrm{H}$ were determined by dry combustion, $\mathrm{N}$ by the automated Dumas method and $\mathrm{O}$ was estimated by difference.

Total acidity, carboxyls, total hydroxyls and carbonyl groups were determined by the methods described by Schnitzer and Khan (1972).

Phenolic hydroxyls were considered to be equal to the difference between the total acidity and the carboxyl groups, whereas alcoholic hydroxyls were considered equal to the difference between total and phenolic hydroxyls.

IR spectra were recorded on $\mathrm{KBr}$ pellets ( $1 \mathrm{mg} \mathrm{FA}+200 \mathrm{mg} \mathrm{KBr}$ ) on a Perkins Elmer Model 621.

UV and visible spectra were recorded on a $0.05 \mathrm{~N} \mathrm{NaHCO}_{3}$ solution with a Hitachi Perkin Elmer Model 124 spectrophotometer. Ash composition was determined by atomic absorption using an Unicam Atomic Absorption spectrophotometer, Model SP 90A.

\section{Pyrolysis}

One milligram of each FA was pyrolyzed in a quartz tube, $30 \mathrm{~mm}$ long and $2 \mathrm{~mm}$ in internal diameter, inserted in a coil ribbon platinum wire of a pyrolysator, Model Pyroprobe 100 CDS. This was attached to a Hewlett Packard Model $5750 \mathrm{G}$ dual-column gas chromatograph with 2 flame-ionization detectors. Sample and reference columns consisted of stainless-steel tubes, approximately $1.8 \mathrm{~m}$ long and $3.1 \mathrm{~mm}$ in diameter (6 ft $\times 1 / 8 \mathrm{in})$, packed with Chromosorb 102. 
The pyrolysis conditions were:

$\begin{array}{ll}\text { Temperature } & 700^{\circ} \mathrm{C} \\ \text { Ramp } & \mathrm{OFF} \\ \text { Interval } & 10 \mathrm{sec} \\ \text { Interface temperature } & 200^{\circ} \mathrm{C}\end{array}$

Chromatographic conditions:

$\begin{array}{ll}\text { Gas } & \mathrm{N}_{2} \text { at } 40 \mathrm{ml} / \mathrm{min} \\ \text { Temperature } & 50-200^{\circ} \mathrm{C}+15 \mathrm{~min} \text { isotherm } \\ \text { Rate } & 10^{\circ} \mathrm{C} / \mathrm{min} \\ \text { Injector temperature } & 250^{\circ} \mathrm{C} \\ \text { Detector temperature } & 300^{\circ} \mathrm{C}\end{array}$

\section{RESULTS}

In Table I are shown elementary compositions of the three FA specimens (FA-1 represents those extracted with $\mathrm{NaOH}, \mathrm{FA}-2$ those extracted with $\mathrm{HCl}$ and FA-3 those extracted with $\left.\mathrm{Na}_{4} \mathrm{P}_{2} \mathrm{O}_{7} / \mathrm{NaOH}\right)$ and the atomic ratios, $\mathrm{H} / \mathrm{C}$ and $\mathrm{O} / \mathrm{C}$.

Differences between the values are small. FA-2 has less $C$ than the other two and FA-3 less $\mathrm{H}$ than FA-1 and FA-2. The largest difference is in the N-content; FA-1 has twice as much as FA-2 and 11/2 times that of FA-3. These relatic nships indicate again that the nature of the extractant affects the N-content of humic substances, the $\mathrm{NaOH}$ extracting the greatest amount (Bremner, 1954; Schnitzer and Skinner, 1968; Swift and Posner, 1972; Vila et al., 1974). The data for the elementary compositions of these FA's are within the range given for this fraction of soil humic substances in Podzols by Schnitzer and Khan (1972).

Functional groups in the three FA's are closely similar (Table II), with very small differences as in elementary compositions. FA-3 has the highest carboxyl content and therefore less phenolic hydroxyls. A similar trend is observed in $\mathrm{HA}$ when it is extracted with $\mathrm{Na}_{4} \mathrm{P}_{2} \mathrm{O}_{7}$ as compared to other extractants (Jacquin et al., 1970; Vila et al., 1974).

\section{TABLE I}

Elementary composition and atomic $\mathrm{H} / \mathrm{C}, \mathrm{O} / \mathrm{C}$ and $E_{4} / E_{6}$ ratios of fulvic acids

\begin{tabular}{lllllllr}
\hline & $\mathrm{C}^{*}$ & $\mathrm{H}^{*}$ & $\mathrm{~N}^{*}$ & $\mathrm{O}^{*}$ & $\mathrm{H} / \mathrm{C}$ & $\mathrm{O} / \mathrm{C}$ & $E_{4} / E_{6}$ \\
\hline FA-1 & 50.2 & 4.6 & 1.7 & 43.5 & 1.1 & 0.65 & 7.05 \\
FA-2 & 48.1 & 4.3 & 0.9 & 46.7 & 1.1 & 0.73 & 11.20 \\
FA-3 & 50.8 & 3.8 & 1.1 & 44.3 & 0.9 & 0.65 & 11.10 \\
\hline
\end{tabular}

*Values in \%. 
TABLE II

Major oxygen containing functional groups of fulvic acids (mequiv./g ash-free)

\begin{tabular}{llllll}
\hline $\begin{array}{l}\text { Total } \\
\text { acidity }\end{array}$ & Carboxyl & $\begin{array}{l}\text { Phenolic } \\
\text { OH }\end{array}$ & $\begin{array}{l}\text { Alcoholic } \\
\text { OH }\end{array}$ & Carbonyl \\
\hline FA-1 & 12.1 & 7.9 & 4.2 & 2.8 & 2.8 \\
FA-2 & 12.6 & 8.6 & 4.0 & 3.3 & 3.8 \\
FA-3 & 12.1 & 9.3 & 2.8 & 3.3 & 2.9 \\
\hline
\end{tabular}

The distribution of oxygen in functional groups is shown in Table III.

Between $94.5 \%$ and $100 \%$ of the total oxygen was in functional groups with more than one half (2/3 in FA-3) of this in carboxyl groups.

The IR spectra (Fig.1) are practically identical for the three FA's, showing no significant differences. All spectra have the characteristic absorption bands of FA: $3400 \mathrm{~cm}^{-1}$ ( $\mathrm{H}$ bonded $\mathrm{OH}$ ), $2950 \mathrm{~cm}^{-1}$ (alipathic $\mathrm{C}-\mathrm{H}$ ), 2600 $\mathrm{cm}^{-1}$ (OH stretching of $\left.\mathrm{COOH}\right), 1725 \mathrm{~cm}^{-1}$ ( $\mathrm{C}=\mathrm{O}$ of $\mathrm{COOH}$ and carbonyl), $1630 \mathrm{~cm}^{-1}$ (aromatic $\mathrm{C}=\mathrm{C}, \mathrm{H}$ bonded $\mathrm{C}=\mathrm{O}$ ), $1400 \mathrm{~cm}^{-1}$ (alipathic $\mathrm{C}-\mathrm{H}$, $\left.\mathrm{COO}^{-}\right), 1200 \mathrm{~cm}^{-1}$ (C-O or $\mathrm{OH}$ of $\left.\mathrm{COOH}\right)$ and $1075 \mathrm{~cm}^{-1}$ ( $\mathrm{Si}-\mathrm{O}$ of silicate).

The UV and visible spectra (not shown here) are featureless, showing no maxima or minima.

The $E_{4} / E_{6}$ ratios (Table I) show remarkable differences. FA-1 has a ratio. of 7.5, comparable to data presented by other authors, but FA-2 and FA-3 have values of the order of 11 . As this ratio has been considered an index of condensation, an increase in condensation is indicated by a decrease in the $E_{4} / E_{6}$ ratio (Kononova, 1966 ). FA-2 and FA-3 could have very slightly condensed aromatic nuclei and be molecularly less complex than FA-1. However, as has been pointed out by Schnitzer (1971) it is necessary to investigate further the validity of the $E_{4} / E_{6}$ ratio for $\mathrm{FA}$.

The electrophoretic migration is identical for the three FA's, and the

\section{TABLE III}

Distribution of oxygen in functional groups

\begin{tabular}{lllllll}
\hline & Oxygen & Carboxyl* & $\begin{array}{l}\text { Phenolic* } \\
\text { OH }\end{array}$ & $\begin{array}{l}\text { Alcoholic* } \\
\text { OH }\end{array}$ & Carbonyl* & $\begin{array}{l}\text { Oxygen } \\
\text { accounted } \\
\text { for }\end{array}$ \\
\hline FA-1 & 43.5 & 58.4 & 15.5 & 10.2 & 10.3 & 94.5 \\
FA-2 & 46.7 & 58.7 & 13.8 & 11.2 & 12.9 & 96.5 \\
FA-3 & 44.3 & 67.3 & 10.2 & 11.9 & 10.6 & 100.0 \\
\hline
\end{tabular}

*Values in \% of oxygen. 


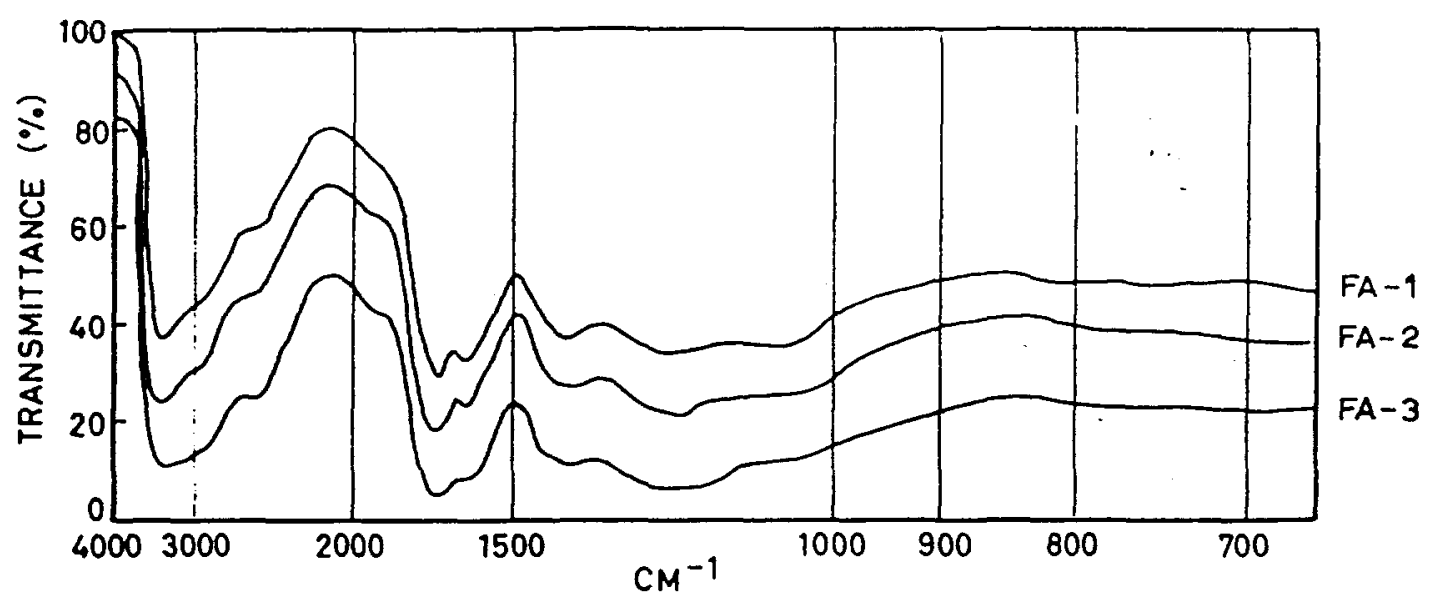

Fig. 1. IR spectra of FA's.

fractionation by Sephadex G-50 and G-100, using water and tris as eluants, produces only one maximum with the same $k_{\mathrm{d}}$.

The ash content and composition are shown in Table IV. The contents are a little high in comparison with other available data (Martin, 1965;

Schnitzer, 1970). The ash composition is conditioned by the extractant employed, reflected in a high $\mathrm{Na}$-content when $\mathrm{NaOH}$ and the mixture $\mathrm{Na}_{4} \mathrm{P}_{2} \mathrm{O}_{7} /$ $\mathrm{NaOH}$ are used and a high $\mathrm{Fe}$ content when $\mathrm{HCl}$ is employed.

The pyrograms of FA's are illustrated in Figs. 2, 3 and 4. As Chromosorb 102 , a porous polymer particularly useful for separating low molecular weight compounds, was packed into the chromatographic column, attention has been given only to such compounds. With the use of different subtractive processes (Innes et al., 1963), retention time, co-chromatography with known compounds and colour reaction, the compounds listed in Table V were identified.

Several of these compounds have been reported in the pyrolysis of humic substances (Wershaw and Bohner, 1969; Kimber and Searle, 1970; Gómez Aranda et al., 1972).

The pyrograms are qualitatively but not quantitatively identical. Taking into account only the major peaks, methane (1) is produced in FA-1 in double the amount of that from FA-2 and three times that from FA-3.

\section{TABLE IV}

Ash-content and percentages of some elements of fulvic acids

\begin{tabular}{llllrrrrl}
\hline & Ash (\%) & $\mathrm{Ca}$ & $\mathrm{Mg}$ & $\mathrm{Na}$ & $\mathrm{Fe}$ & $\mathrm{Mn} \cdot \mathrm{Zn}$ & $\mathrm{Cu}$ \\
\hline FA-1 & 5.6 & 1.6 & 0.3 & 20.9 & 2.5 & 0 & 0.04 & 0.05 \\
FA-2 & 5.6 & 0.4 & 0.1 & 0.0 & 53.5 & 0 & 0.04 & 0.12 \\
FA-3 & 3.8 & 0.7 & 0.1 & 30.7 & 0.7 & 0 & 0.15 & 0.26
\end{tabular}

Values of the elements are in $\%$ of ash. 

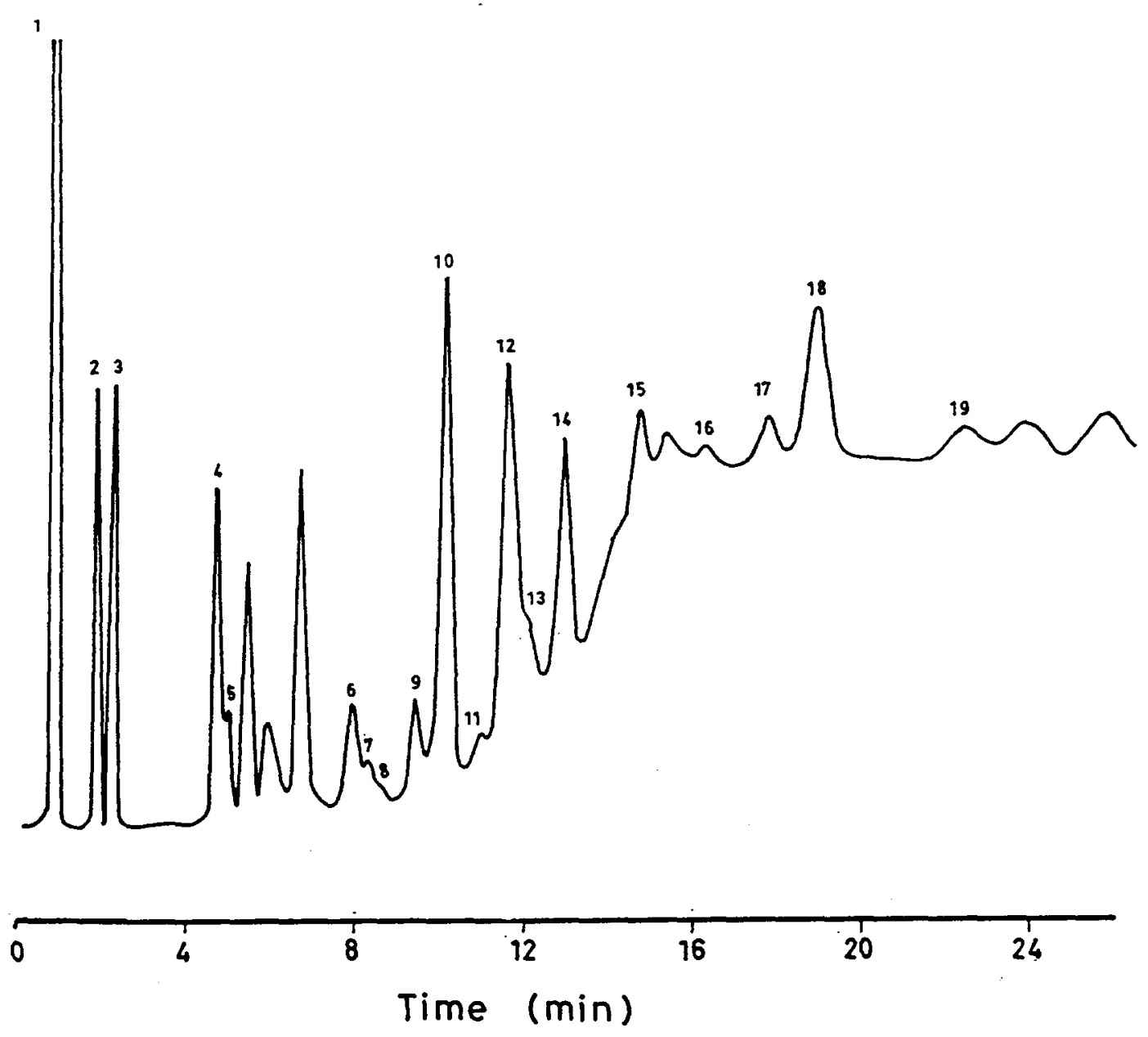

Fig.2. Low-boiling-point compounds pyrogram of.FA-1.

Ethylene (2) and ethane (3) are produced in similar amounts in FA-1 but not in FA-2 and FA-3. Propylene (4) and propane (5) are formed in greater amounts from FA-1 than from the other two FA's. Benzene (14) and toluene (17) are produced in larger amounts from FA-2 than from the other two specimens, as is also true of furfural alcohol (18).

It is difficult to think that all compounds produced are derived directly from the FA molecules. Probably some of them are produced by reactions among component radicals, as Madorsky (1964) pointed out for other organic polymers. This possibility gains support when methylated FA is pyrolyzed (Fig.5). Only the data for methylated FA-1 are shown because the pyrograms for methylated FA-2 and FA-3 are similar.

The pyrogram is qualitatively identical to that of the original FA but the peak heights of alkanes increase greatly. A new peak, identified as methanol, appears, derived from the methoxyl groups introduced in the methylation process.

Table VI shows the percentages of materials pyrolyzed. These values agree 


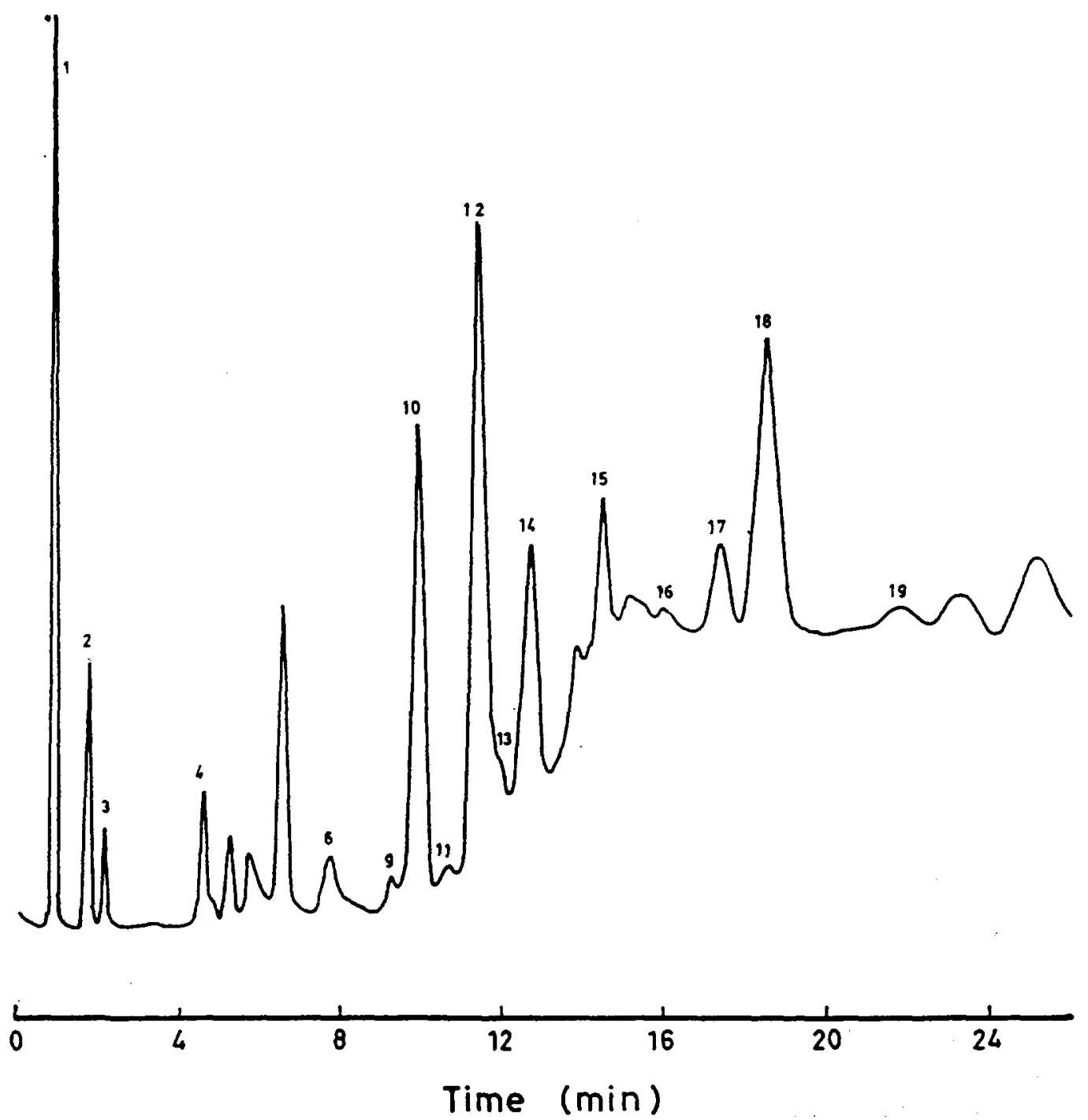

Fig.3. Low-boiling-point compounds pyrogram of FA-2.

with those reported by Kimber and Searle (1970).

The elementary composition and atomic ratios, $\mathrm{H} / \mathrm{C}$ and $\mathrm{O} / \mathrm{C}$, of FA's residues after pyrolysis are shown in Table VII.

The FA residues contained more $\mathrm{C}$ and $\mathrm{N}$ but less $\mathrm{H}$ and $\mathrm{O}$ than did the original samples. The FA-2-Py (the residue after pyrolysis of FA-2) has a high C-content which corresponds with the large amount of pyrolyzed material, whereas those of FA-1-Py and FA-3-Py are similar. After pyrolysis 60, 100 and $100 \%$ of the original nitrogen remained in FA-1-Py, FA-2-Py and FA-3-Py, respectively (Table II).

The atomic $\mathrm{H} / \mathrm{C}$ ratios of the residues are half of those of the originals, i.e. there is an increase in aromaticity. This is also indicated by the $E_{4} / E_{6}$ ratios (Table VI), the values for FA-1-Py and FA-2-Py being within the range for HA (Kononova, 1966; Ortiz de Serra and Schnitzer, 1972). 


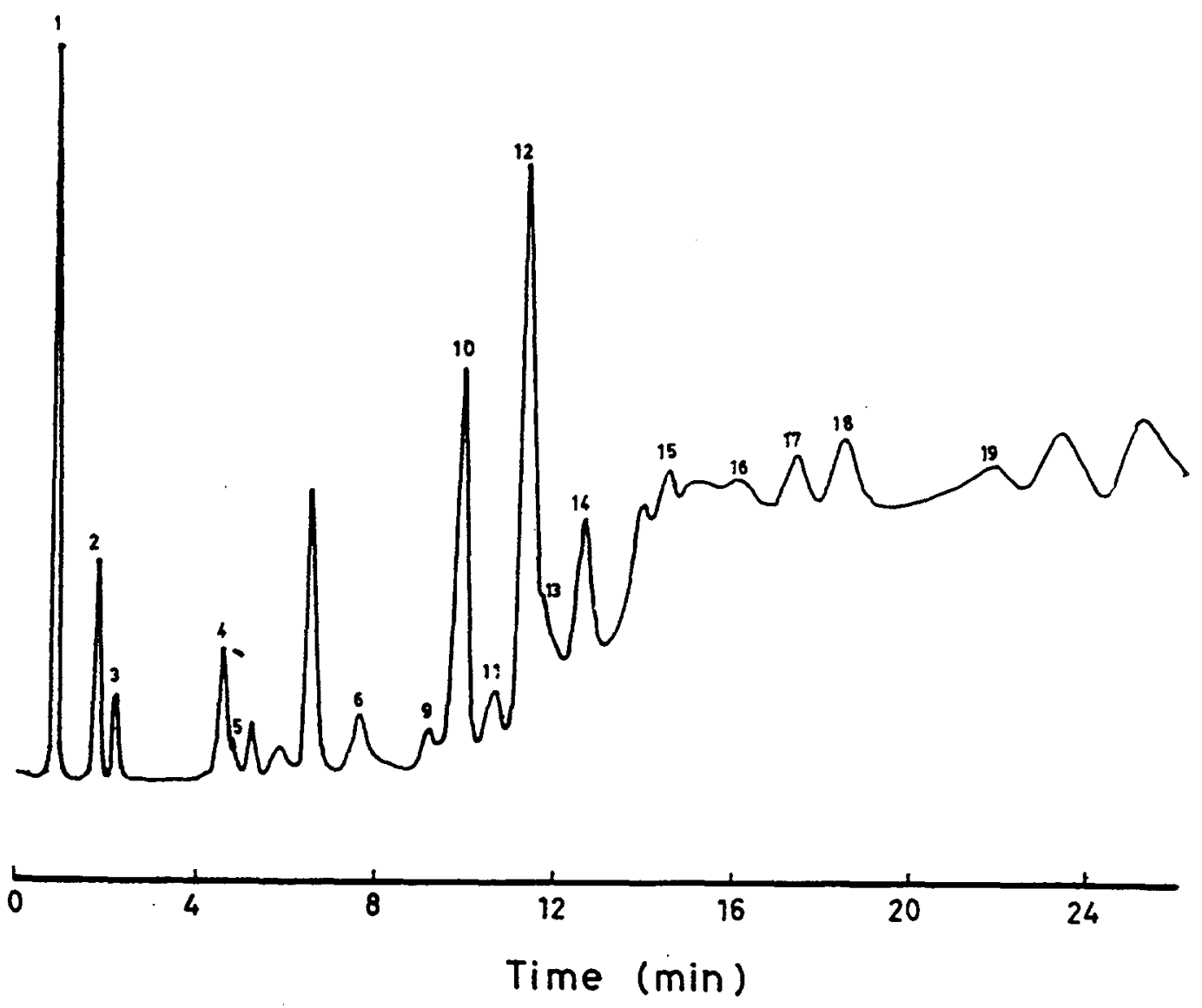

Fig.4. Low-boiling-point compounds pyrogram of FA-3.

If the atomic ratios, $\mathrm{H} / \mathrm{C}$ and $\mathrm{O} / \mathrm{C}$, of the residues of pyrolysis are plotted according to the diagram of Van Krevelen (1950), the main pyrolysis reaction appears to be dehydration, as pointed out Schnitzer and Hoffman (1965) for FA and HA.

Appearances of the residues of pyrolysis also show some differences in that FA-1-Py and FA-2-Py resemble the original samples, whereas particles of FA-3-Py seem to have been subject to swelling.

\section{TABLE V}

Low-boiling-point compounds from pyrolysis of fulvic acids

\begin{tabular}{|c|c|c|c|c|}
\hline Alkanes & Olefins & Aromatics & Inorganics & Others \\
\hline $\begin{array}{l}1 \text { methane } \\
3 \text { ethane } \\
5 \text { propane } \\
6 \text { butane } \\
11 \text { pentane } \\
14 \text { hexane } \\
16 \text { heptane }\end{array}$ & $\begin{array}{l}2 \text { ethene } \\
4 \text { propylene } \\
7 \text { butene-2-cis } \\
8 \text { butene-2-trans } \\
9 \text { pentene- } 1\end{array}$ & $\begin{array}{l}15 \text { benzene } \\
17 \text { toluene } \\
19 \text { phenol }\end{array}$ & $\begin{array}{l}\mathrm{CO} \\
\mathrm{CO}_{2} \\
\mathrm{H}_{2} \mathrm{O}\end{array}$ & $\begin{array}{l}10 \text { acetone } \\
12 \text { acetic acid } \\
13 \text { furan } \\
18 \text { furfural } \\
\quad \text { alcohol }\end{array}$ \\
\hline
\end{tabular}




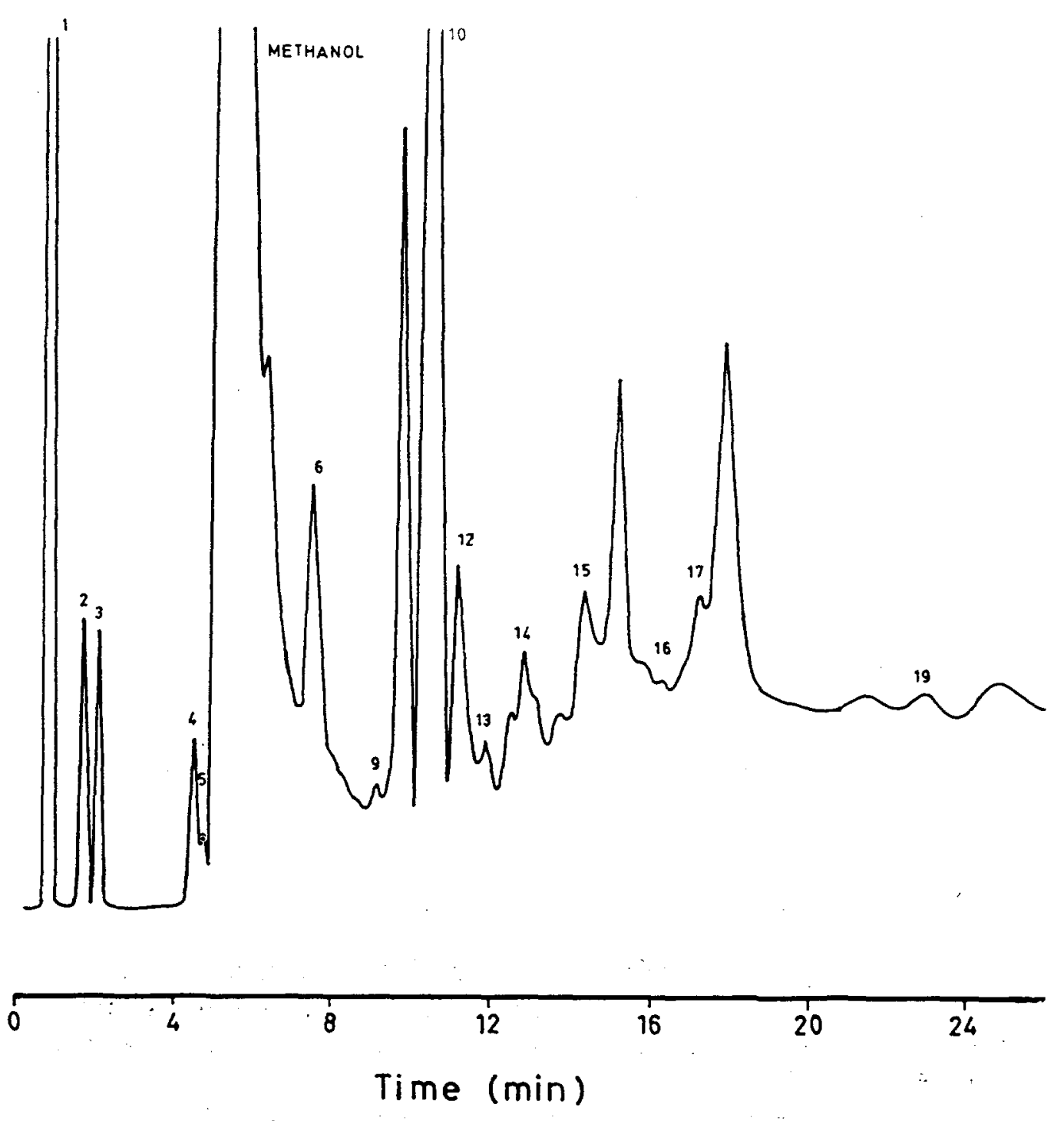

Fig.5. Low-boiling-point compounds pyrogram of FA-1 methylated.

Fig. 6 shows the IR spectra of the pyrolysis residues. Differences appear which were not observed for the original specimens. FA-1-Py shows absorption bands at $3400 \mathrm{~cm}^{-1}$, a slight inflection at $1725 \mathrm{~cm}^{-1}, 1600 \mathrm{~cm}^{-1}, 1375 \mathrm{~cm}^{-1}$, $1100 \mathrm{~cm}^{-1}$ and $1050 \mathrm{~cm}^{-1}$. The spectrum of FA-2-Py shows much the same bands, but that at $3400 \mathrm{~cm}^{-1}$ has less absorption, that at $1725 \mathrm{~cm}^{-1}$ has a high intensity, and that at $1050 \mathrm{~cm}^{-1}$ has disappeared. In FA-3-Py the band at $3400 \mathrm{~cm}^{-1}$ is smaller than in the two preceeding samples and the band at $1725 \mathrm{~cm}^{-1}$ is the highest of the three FA residues. The intensity of this latter band grades in the order: FA-1-Py $<$ FA-2-Py $<$ FA-3-Py, which is in an inverse relationship to the production of low molecular weight compounds on pyrolysis.

The UV and visible spectra, as in the original specimens, are featureless, showing no maxima or minima. 
TABLE VI

Percentage of material pyrolyzed and $E_{\downarrow} / E_{c}$ ratios of residues

\begin{tabular}{lll}
\hline & $\begin{array}{l}\text { pyrolyzed material } \\
(\%)\end{array}$ & $E_{4} / E_{6}$ \\
\hline FA-1 & 55.4 & \\
FA-2 & 60.6 & 3.8 \\
FA-3 & 51.7 & 4.7 \\
\hline
\end{tabular}

TABLE VII

Elementary composition and atomic ratios of pyrolysis residues

\begin{tabular}{lllllll} 
& C & H & N & O & H/C & O/C \\
\hline FA-1-Py & 63.9 & 2.9 & 2.3 & 30.9 & 0.55 & 0.36 \\
FA-2-Py & 74.1 & 3.1 & 2.3 & 20.5 & 0.50 & 0.21 \\
FA-3-Py & 64.7 & 2.9 & 2.1 & 30.3 & 0.54 & 0.35 \\
\hline
\end{tabular}

\section{CONCLUSIONS}

Sodium hydroxyde, hydrochloric acid and the mixture of sodium pyrophosphate and sodium hydroxyde extract the same quantities of fulvic acids from the $\mathrm{B}_{\mathbf{h}}$ :horizon of a Podzol. The elementary composition, major oxygen functional groups, as well as IR spectra, are very similar for the three fulvic acids: Only the $\mathrm{N}$-content of the FA extracted with sodium hydroxyde is higher than those of the other two specimens. The $E_{4} / E_{6}$ ratio of fulvic acids extracted with sodium hydroxide is also different and smaller than that of the other two.

The usual parameters applied in the studies of the humic substances do not indicate significant differences among the three fulvic acids.

The pyrograms of low-boiling-point compounds are quantitatively distinct. It is possible that not all the identified compounds are released from the fulvic-acid molecules by thermal fission, although part of them may be produced by radical or chain reactions, isomerisation, dehydrogenation, etc. catalyzed by some of the ash components (Martín, 1975).

The pyrolysis patterns of the fulvic acids and the percentages of pyrolyzed material, on the one hand, and the $E_{4} / E_{6}$ ratios and IR spectra of the residues of of pyrolysis, on the other, indicate that their structures differ, though perhaps only slightly, as occurs in isomeric compounds (Janak, 1960; Jennings and Dimick, 1962).

The pyrolysis gas chromatography of fulvic acids is a sensitive technique 


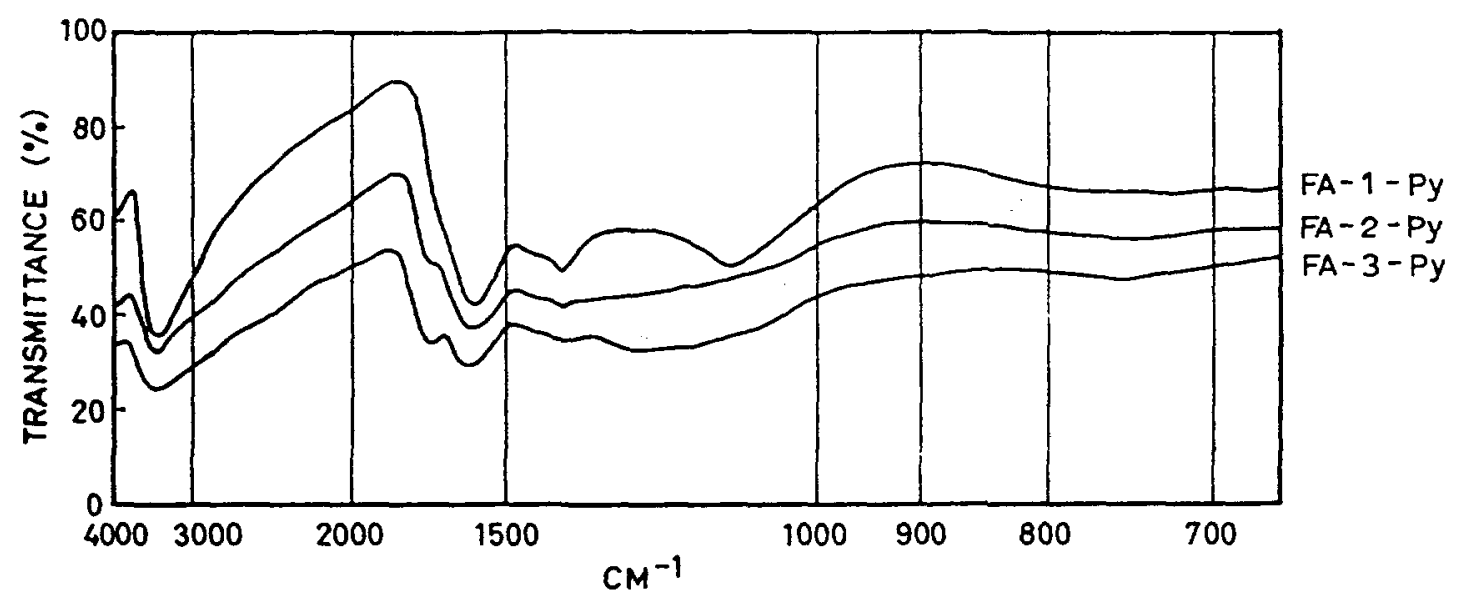

Fig.6. IR spectra of FA residues after pyrolysis.

for uncovering structural changes. These may be induced by the reagents used to extract the humic compounds, even with the practice of care and the application of the same criteria for purification. Alternately, other organic substances (non-humic materials) might be co-extracted and incorporated among the molecules, e.g. N-containing compounds.

\section{ACKNOWLEDGEMENT}

The author thanks Mrs. T. Verdejo for technical assistance.

\section{REFERENCES}

Bremner, J.M., 1967. Nitrogenous compounds. In: A.D. McLaren and G.H. Peterson (Editors), Soil Biochemistry, 1. Marcel Dekker, New York, N.Y., p. 45.

Dubach, P. and Mehta, N.C., 1963. The chemistry of soil humic substances. Soils Fert., 26: 293-300.

Forsyth, W.G.C., 1947. Studies on the more soluble complexes of soil organic matter. Biochem. J., 41: 176-181.

Gómez Aranda, V., Osacar Flaquer, J. and Revuelta Blanco, G., 1972. Study by pyrolysis gas chromatography of products from humic substances. An. R. Soc. Esp. Fis. Quim., 68: 1407-1410 (in Spanish).

Guiochon, G., 1968. On the conditions of flash pyrolysis of polymers as used in pyrolysis gas chromatography. Anal. Chem., 40: 998-1000.

Innes, W.B., Mambrick, W.E. and Andreatch, A.J., 1963. Hydrocarbon gas analysis using differential chemical adsorption and flame ionization detector. Anal. Chem., 35: 11981203.

Jacquin, F., Calvez, C., Dormaar, J.F. and Metche, M., 1970. Contribution to the study of extraction procedures and characterization of humic compounds. Bull. Assoc. Fr. Etude Sol, $4: 27-38$.

Janak, J., 1960. Identification of the structure of non-volatile organic substances by gas chromatography of pyrolytic products. Nature, 185: 684-686.

Jennings Jr.,E.C. and Dimick, K.P., 1962. Gas chromatography of pyrolytic products of purines and pyrimidines. Anal: Chem. 34: 1543-1547.

Kimber, R.W.L. and Searle, P.L., 1970. Pyrolysis gas chromatography of soil organic matter. Geoderma, 4: 47-71. 
Kononova, M.M., 1966. Soil Organic Matter. Pergamon, Oxford, 2nd ed.

Madorsky, S.L., 1964. Thermal Degradation of Organic Polymers. Interscience, New York, N.Y., pp. 96-115.

Martin, F., 1965. Study of two fulvic acids from podzolic soils. An. F fol. Agrobiol., 24: 399-406 (in Spanish).

Martin, F., 1975. Pyrolysis gas chromatography of humic substances from different origin. Z. Pflanzenernähr. Bodenk., 4: 407-416.

Ortiz de Serra, M. and Schnitzer, M., 1972. Extraction of humic acids by alkali and chelating resin. Can. J. Soil Sci., 52: 365-374.

Posner, A.M., 1966. The humic acids extracted by various reagents from a soil. I. Yield inorganic components and titration curves. J. Soil Sci., 17:65-78.

Schnitzer, M., 1970. Cinaracteristics of organic matter extracted from Podzol B horizons. Can. J. Soil Sci., 50: 199-204.

Schnitzer, M., 1971. Characterization of humic constituents by spectroscopy. In: A.D. McLaren and J. Skujins (Editors), Soil Biochemistry, 2. Marcel Dekker, New York, N.Y., p. 63.

Schnitzer, M. and Hoffman, I., 1965. Thermogravimetry of soil humic compounds. Geochim. Cosmochim. Acta., 29: 859-870.

Schnitzer, M. and Skinner, S.I.M., 1968. Alkali versus acid extraction of soil organic matter. Soil Sci., 105: 392-396.

Schnitzer. M. and Khan, S.U., 1972. Humic Substances in the Environment. Marcel Dekker, Ntw York, N.Y.

Swift, R.S. and Posner, A.M., 1972. The distribution and extraction of soil nitrogen as a function of soil particle size. Soil Biol. Biochem., 4: 181-186.

Theng, W.K.G., Wake, J.R.H. and Posner, A.M., 1967. The humic acids extracted by various reagents from a soil. J. Soil Sci., 18: 349-363.

Van Krevelen, D.W., 1950. Graphical statistical method for the study of structure and reaction processes of coal. Fuel, 29: 269-284.

Vila, F.J.G., Saiz Jimenez, C. and Martín, F., 1974. Comparative studies on humic acids extracted with two alkaline agents. Agrochimica, 18: 164-172.

Wershaw, R.L. and Bohner, G.E., 1969. Pyrolysis of humic and fulvic acids. Geochim. Cosmochim. Acta., 33: 757-762. 